\title{
Geographic Information Systems (GIS) in Urban Planning
}

\author{
Ph.D. Sonila Xhafa \\ State University of Tirana, Geography Department \\ email: sonilaxhafa@gmail.com \\ Ph.D. Albana Kosovrasti \\ State University of Tirana, Geography Department \\ email: sonilaxhafa@gmail.com
}

\begin{abstract}
Geographic information systems can be defined as a intelligent tool, to which it relates techniques for the implementation of processes such as the introduction, recording, storage, handling, processing and generation of spatial data. Use of GIS in urban planning helps and guides planners for an orderly development of settlements and infrastructure facilities within and outside urban areas. Continued growth of the population in urban centers generates the need for expansion of urban space, for its planning in terms of physical and social infrastructures in the service of the community, based on the principles of sustainable development. In addition urbanization is accompanied with numerous structural transformations and functional cities, which should be evaluated in spatial context, to be managed and planned according to the principles of sustainable development. Urban planning connects directly with land use and design of the urban environment, including physical and social infrastructure in service of the urban community, constituting a challenge to global levels. Use of GIS in this field is a different approach regarding the space, its development and design, analysis and modeling of various processes occurring in it, as well as interconnections between these processes or developments in space.
\end{abstract}

Keywords: GIS, urban planning, territory management, sustainable development etc.

\section{Introduction}

People have used maps for centuries to reflect the terrestrial environment and the processes that occur in it, to show the locations and measure distances, for navigation, for exploration and illustration of the phenomena, for communication in public and private sector.

But which is more important is its role in reflecting the relations between objects in the real world and betwen them and space, as well as their planning and developmental models in territory.

GIS are part of spatial information systems. They process, and generate spatial information (through cartographic and photogrametric products, statistical reports etc.).

GIS products mainly with spatial containing, are result of the integration of spatial information and other data with multithematic character. In GIS real world models generally come in mapping and imaging formats .

Almost in any field of study and of human activity, maps, aerial photos, satellite images

are necessary products and analytical instruments for many aspects of academic and professional life. Nowadays GIS are expanding quite their range of functions and applications. More than 60 disciplines and departments in colleges and universities in the world have integrated GIS within their curricula and research, as the science of geography, geology, archeology, agriculture, journalism, biology, economics, engineering, political science, computer science, urban planning, environment etc.

Uses of GIS continue to grow beyond businesses, industries, universities and government sector. In

current economic conditions and urban developments such as in regional levels, as well as in global level, the demand for the use of the natural resources (soil, water, vegetation,) is growing, which dictates even in many cases their irrational use through several informal actions. In these conditions, is necessary their good management. Human community has recognized the need for better sharing of resources between them for all life forms and activities. GIS plays an essential 
role in providing optimum models of land use and its resources. It is important to know where these resources are located (spatial data), their relations with objects, events and other phenomenas, the conditions in which they develop, ways how you can continually monitor them, as to register and arrange in such a way as to recover them at any moment where we need their use etc. Use of GIS in urban planning helps and guides planners for an orderly development of settlements and infrastructure facilities within and outside urban areas.

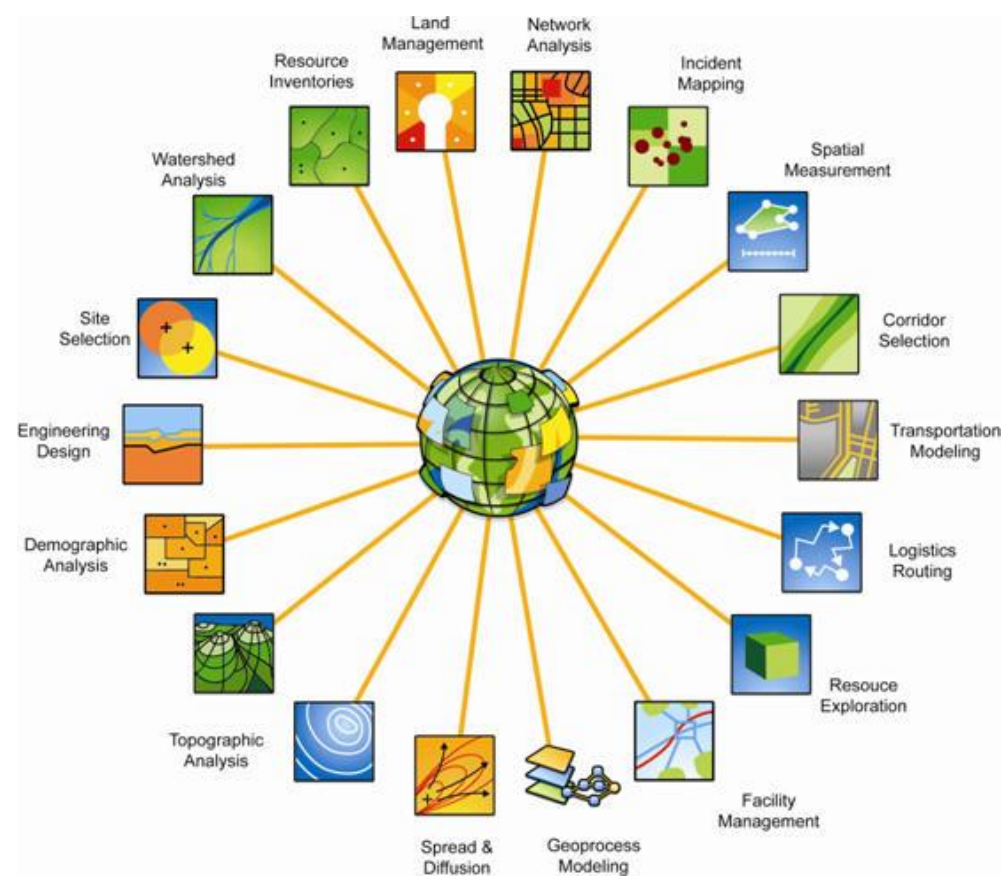

Source: http://www.directionsmag.com/images/newsletter/2011/01_week1/world_lg.jpg

In this context, its use in urban planning is indispensable given that in the world live 7.25 billion people, where $53.7 \%$ of them live in urban centers ${ }^{1}$. This growth dictates the need for urban spatial planning based on the principles of sustainable development. Nowadays territorial development, are affected from population growth beyond the carrying capacity of the territory, from global warming , social conflicts, human development, economic development activities at the expense of natural spaces , loss of biodiversity and environmental pollution problems. Such situations are common in daily activity together with their complexity and their severity constituting the emergency challenges in the future in terms of their solution.

In this context, is necessary the possession of full knowledge of the territory, mainly in terms of its planning and its development in the future based on the principles of sustainable development. GIS provide an enabling environment in which the spatial and attributive data are recorded and stored, which are used in every field of study.

Today urban life is facing multiple challenges, such as pollution and traffic , poor access to public services etc. , challenges which are addressed to the planning process, which is more fast, efficient and with more quality using GIS technology .

Use of GIS in this area is an approach and a different opinion regarding the space, its development and its design, analysis and modeling of various processes occurring in it, as well as interconnections between these processes or developments with space. Solutions that provides GIS in urban planning can affect the growth of the design and planning of the territory having the spotlight on the community , the further development of economic poles, improving the quality of life in general , the growth of social service planning, etc .

\footnotetext{
${ }^{1}$ Current world population. United Nations, Department of Economic and Social Affairs. 2014
} 


\section{Brief historical overview of the use of GIS in urban planning}

The level of development of all information systems has been high, and therefore in this context is not the exception GIS. GIS as a multifunctional set and consequently with an intensive use in different areas, after 1990, GIS progressed with specific applications in different fields, initially as archive systems, analysis systems, presentation systems, and finally as the decision-making systems.

The genesis of the use of GIS in urban planning, is related to chaotic transformations that suffered the urban city and industrial centers in the mid nineteenth century. At the end of this century, the necessity of implementation of GIS in urban planning came as a necessity of achieving territorial decisions by evaluating a number of factors and conditions at the same time to arrive at an optimal result that reflects adequate planning goals.

In this period, urban planners widely used archive and analysis context of GIS. Decision- making in this period rely on statistical analysis, but also spatial analysis relying on existing maps.

Manual processing of data in this period limited the spatial analysis. In the early 1970 appeared the first models of the digital data mapping. Computer systems provide tools and techniques for automated processing of data with significant volume. In this period were built the first foundations of today's concepts and applications of GIS in urban planning. The transition from analog formats of graphic data in digital ones, through geometric representations (point - for settlements , polyline-for roads and polygon - for surfaces), in one coordinate system gave a new incentive this process in general, and helped the process of re- design of the rapid changes in the territory. Within a short time, many developing countries enabled the updating of existing urban maps.

A big role to the urban planification throughout GIS, played the functioning for the first time in USA of the Landsat satellite. It was used to capture and record in time spatial data at global level. This event encouraged the orientation of searchings for improvements in data structuring and analyzing.

After 1980, SMBD ${ }^{1}$ were developed from which was attained the codification and indetification of geographical features in territory, as well as main infrastructural urban objects, which provided the fastest extraction of results regarding these features or a given object. Nowdays, research in urban planification were orientated in issues linked to accuracy, structuring, availability of data, as well as their integration in other fields.

Since the early 1980s, there was a significant increase in the installation of GIS in different levels of urban planning in developing countries, especially in Europe and North America, and later in countries in developement after 1990.

During the 1990s, attention was directed to the depth spatial analysis for urban planning, where GIS was structured with analytical systems for mathematical and statistical solutions .

Integration of GPS and Remote Sensing in GIS, the massive use of aerial photos and satellite imagery as data sources, improved the analysis in urban planning, as well as increased the efficiency in decision making .

Today GIS is increasingly accessible, constituting an important tool for urban planning in terms of integration of data from different sources to provide information necessary for effective decision-making. GIS technology correlates a wide range of variables to arrive at more effective decision making in the territory.

\section{The use of GIS in urban planning}

GIS products have content space (mainly geographical). At the foundation of the functions of GIS stand spatial analysis. GIS are mainly used in land use planning, service management, ecosystem modeling, assessment and planning of landscape, transport and infrastructure planning, market analysis, evaluation of real estate etc.

Urban planners use GIS technology in monitoring, development and implementation of their projects in service to facilitate the decision - making process. In this context the role of GIS in urban planning takes place through the growth and

${ }^{1}$ database management system 
development of archive, management, analytical and modeling instruments. All these functions have placed GIS as one of the implementing and comprehensive techniques in many areas.

\subsection{GIS as an archive and inventory system}

In all contents of GIS terminology, what is important is the term geo - information. In fact the term geo - information is used simultaneously with the use of automated procedures for the development of information systems for data with spatial context. In this context becomes more important the necessity not only for geo-information production, but also for archiving of the data. From here ran the database concept. Based on functions of Database System, a GIS operates and analyzes the data, but initially registers and archives them.

During urban planning and territorial designs, GIS provides archiving of voluminous and multi - thematic data closely associated with the geographical reference in the service of specific applications.

Database System in GIS, initially has archive functions that should be constantly maintained, so that data could be safe and durable so they could be used at any period of need. A major influence in building of the database in urban planning, have the maps of real estate assessment which provides a variety of data and a comprehensive database on the location of the property, their ownership, prices, proximity of the property with social facilities, material of construction, number of floors, covering with infrastructure, risk factors etc.

The system of storage and retrieval of data in GIS organizes data as spatial and attributive data, so the updateing, analysing and decision-making can be carried out as soon as possible.

GIS inventory and classify data based on a predetermined criterion. Planners can also extract data from the database derived from modeling and spatial analysis. Some GIS use database management system to maintain their attributes associated with the corresponding topology and spatial context .

GIS organizes thematic spatial data through various Database formats, like Excel, Access, SQL, ORACLE etc. , which labeled in GIS as Geo - database which are important in urban planning.

In database management system there are three types of data: the location of objects (defined through reference coordinate system), the attributes associated with them (attributes of objects) and relationships that arise through spatial reference and features of one or several objects with other objects .

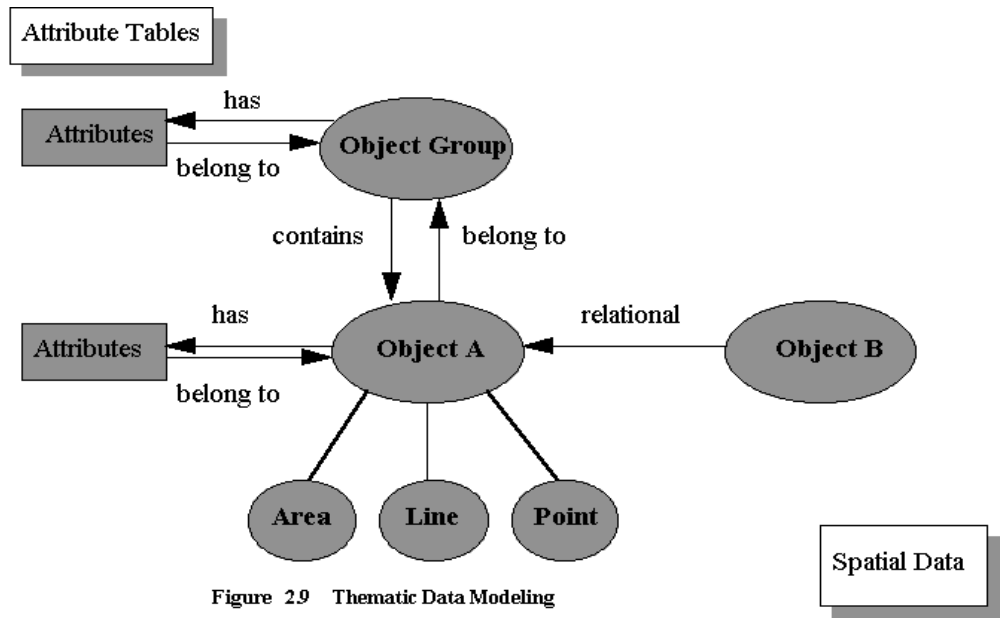

Fig.3. Organization and modeling of data in GIS. Burimi: http://cret.cnu.edu.cn

This type of organization of data is important in urban planning since the residences are associated with social infrastructures the road with the city, a city with another city etc. 
SIG throughout cartographic products and spatial analyses enables:

- monitoring, management and periodic maintenance of social and physical infrastructure in urban centers and beyond; (map 1)

- implementation of integrated analyzes for full coverage of the community with public infrastructure, compilation of alternatives for a sustainable distribution of social and economic facilities in order to increase the accessibility of community in these services;

- $\quad$ preparation prognosis plans of management of infrastructure according the needs of the community based on the future trends of demographic growth and integrated analysis territory / population / infrastructure;

- decision-making, management and solution in time of conflict situations in the territory in case of misuse;

- monitoring, diagnosis of the territory, especially in spaces with the lack of public infrastructure, in spaces inclined for potential territorial developments, in exclusion space development, in urban spaces planned for reclamation and environmental regeneration etc.

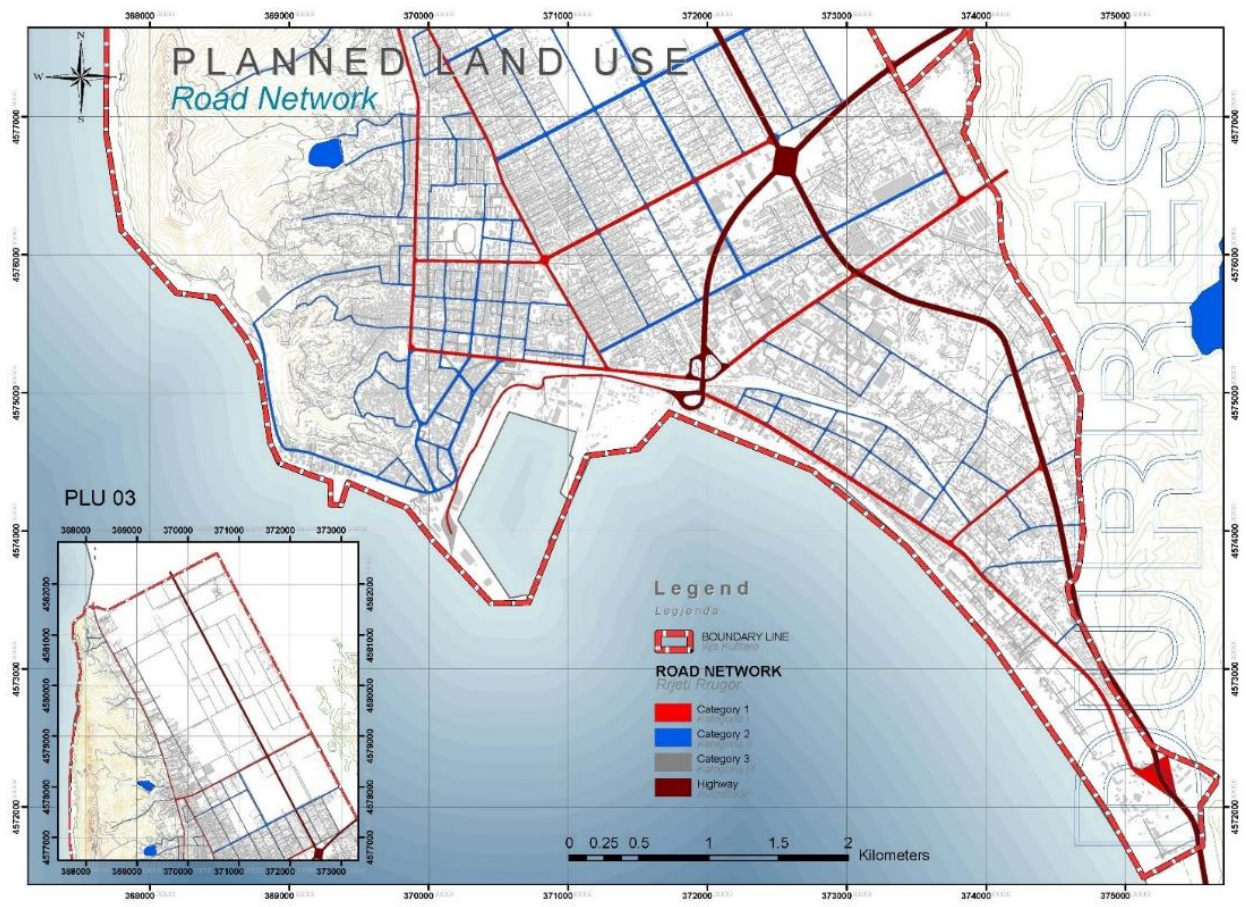

Map 2: Road infrastructure. Urban Planning Office. Municipality of Durrës

3.3. GIS as an analytical system 
GIS use archive database for compilation of queryes (question and answer) that serves for spatial analysis such as: What are the least populated areas within $70 \mathrm{~km}$ radius distance from the town, or what are the areas with the highest consumption in the seaside resort; which are health centers located $500 \mathrm{~m}$ from the residential center. (map 2)

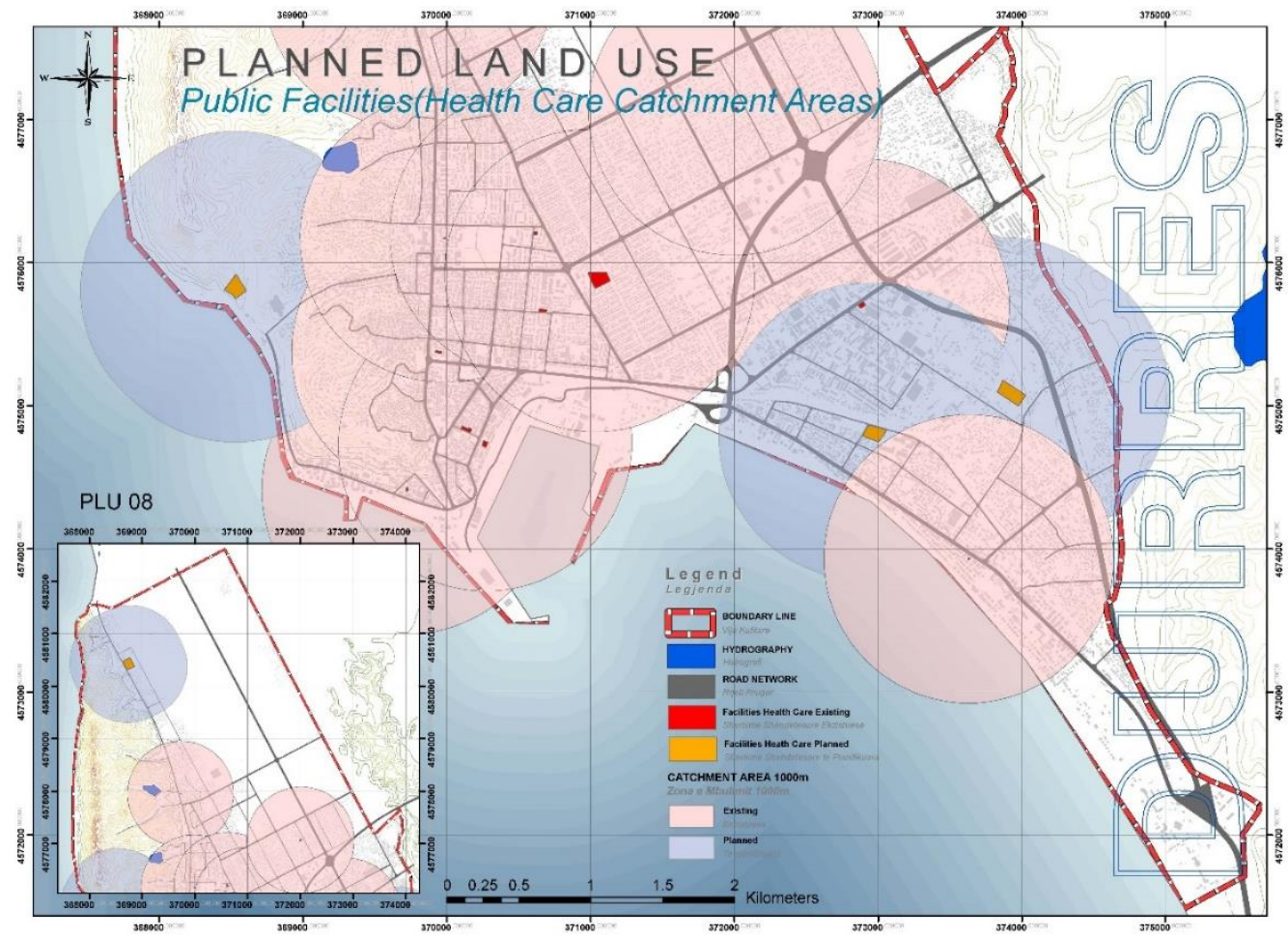

Map 2: Current and planned health infrastructure in the town of Durres (Buffer-Arc GIS 9.0 methodology). Cooperative product with Urban Planning Office (Municipality of Durres) in the function of Lamp Project on the long-term planning in urban spaces and territory regulation, January, 2007

The goal of GIS is that any specific data out of general database could serve for one primary purpose, to develop a unique geographical analysis. GIS is a powerful tool for the implementation of integrated analysis and trend analysis.

GIS is given emphasis in his analytical skills, or in its application to solve specific issues in various fields, but also in scientific research applications. Such applications come to the users from the simples formats to integrated formats for achievement of specific purposes In this context, Geographic Information Systems are characterized by :

- ability of using voluminous data, and with specific purpose in service to analysis process. In this case, often the data collected are stored and archived for a specific purpose, and used for analysis within a project with specific content.

- $\quad$ great analytical bbilities, mainly in statistical and modeling applications.

The purpose of the analytical system in GIS is building a clear understanding on relations between spatial position and geographical phenomenon. Its functionality related to urban modeling enables: linkages, etc.

zoning of urban space, based on the function and territorial linkages, infrastructure linkages, environmental 
classification of urban space, based on the type of strategies to be followed today and in the future (emergency intervention strategies, assessment strategies , protection and regeneration strategies, etc).

building a functional structural scenario, determining the exact size of the buildings and facilities services in the future, as well as defining the environmental and infrastructure connecting structures, etc.
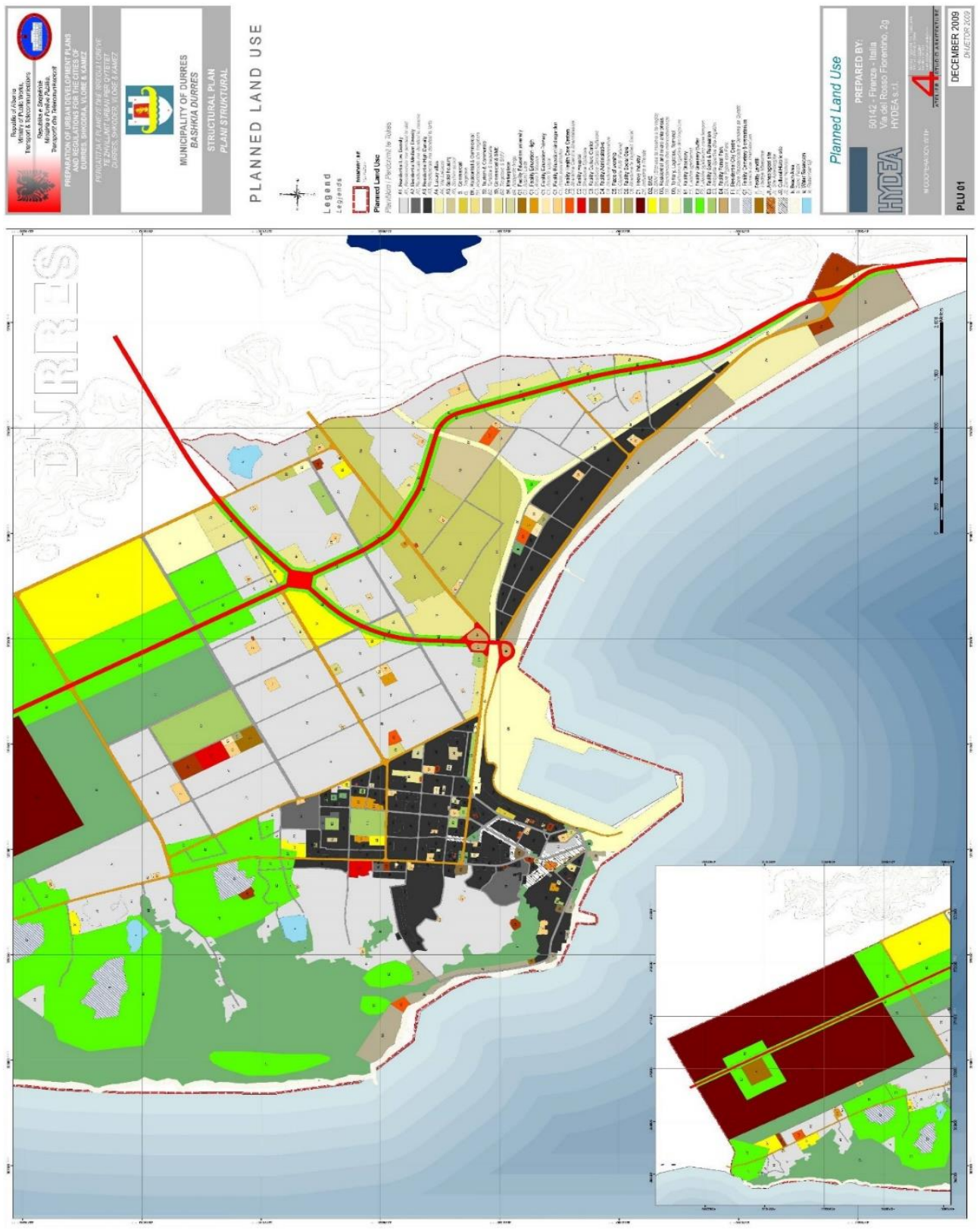

Map 3: Land use in the town of Durres. Municipality of Durres 


\subsection{GIS as a decision-making system}

GIS enables us to see, to understand, to interpret and visualize data in different forms, where we can find various spatial correlations, patterns, and trends in the form of maps, atatisical reports and charts, etc. In this context it is an important decision-making tool in various fields. GIS is able to design possible alternatives and future development of the territory, of population, of economy development etc . Applications of GIS in support decision making allow:

designing different alternatives of actions in the territory, through the examination of the data with different thematic content, which are integrated with each other and are related to the spatial context.

linking data with different thematic patterns in territory development models

designing projections of triad population/area/economy in the future

designing of building models of the urban territory, land-use models, evaluation and expertise models of the territory, offering quality, efficient , fast and accurate products that facilitate the decision making process

In conclusion, the use of GIS in urban planning has led to :

use of qualitative analytical products, and consequently effective decision making; higher efficiency in the extraction of spatial information, and therefore qualitative analysis; use of a wide range of multi - thematic data in the service of decision making in urban planning; improve the quality of spatial analysis process and of public service in urban planning institutions; Increasing consciousness on the territory and spatial thinking in community

\section{Bibliography:}

[1] Batty M 1990 Information systems and technology for urban and regional planning in developing countries: a review of UNCRD's research project, Vol. 1. Nagoya, Japan, United Nations Centre for Regional Development

[2] BURROUGH, P.A. and MCDONNELL (1998) Principles of Geographical Information Systems, Spatial Information Systems Series. New York/Oxford: Oxford University Press.

[3] ESRI, GIS for Urban and Regional Planning, January 2011

[4] GJATA G., Imazhet satelitore. Teledeteksioni, Tirane 2007

[5] NIKOLLI P., Vështrim mbi të dhënat dhe informacionin gjeografik, Studime Gjeografike 13, Tiranë 2002.

[6] XHAFA S. and HASANI B., Urban planning challenges in the peripheral areas of Durres city (Porto Romano), Mediterranean Journal of Social Sciences, Vol.4 (2103) No.10: 605-614 